\title{
Hallazgos microscópicos en la autopsia del cuello: casuística del Instituto de Toxicología en casos de ahorcadura, estrangulación y otras lesiones cervicales.
}

Microscopic findings in neck's autopsy: hanging, strangulation cases and other cervical lesions, based on our experience in the Institute of Toxicology.

Ma S. Sánchez de León Robles

Cuad Med Forense 2001;23:31-47

El estudio de las lesiones cervicales en casos sospechosos de criminalidad, es una cuestión que no siempre está clara con el examen macroscópico de la autopsia y requiere ampliar información, confirmar o incluso descartar dichas lesiones, a través de estudios complementarios: el estudio histopatológico es uno de ellos. En el artículo se hace una exhaustiva descripción y valoración de los hallazgos microscópicos en piel, paquetes vasculares (arterias carótidas y venas yugulares internas), músculos esternocleidomastoideos y complejo hioides-laringe. Igualmente se exponen una serie de imágenes histopatológicas que aquí mostramos.

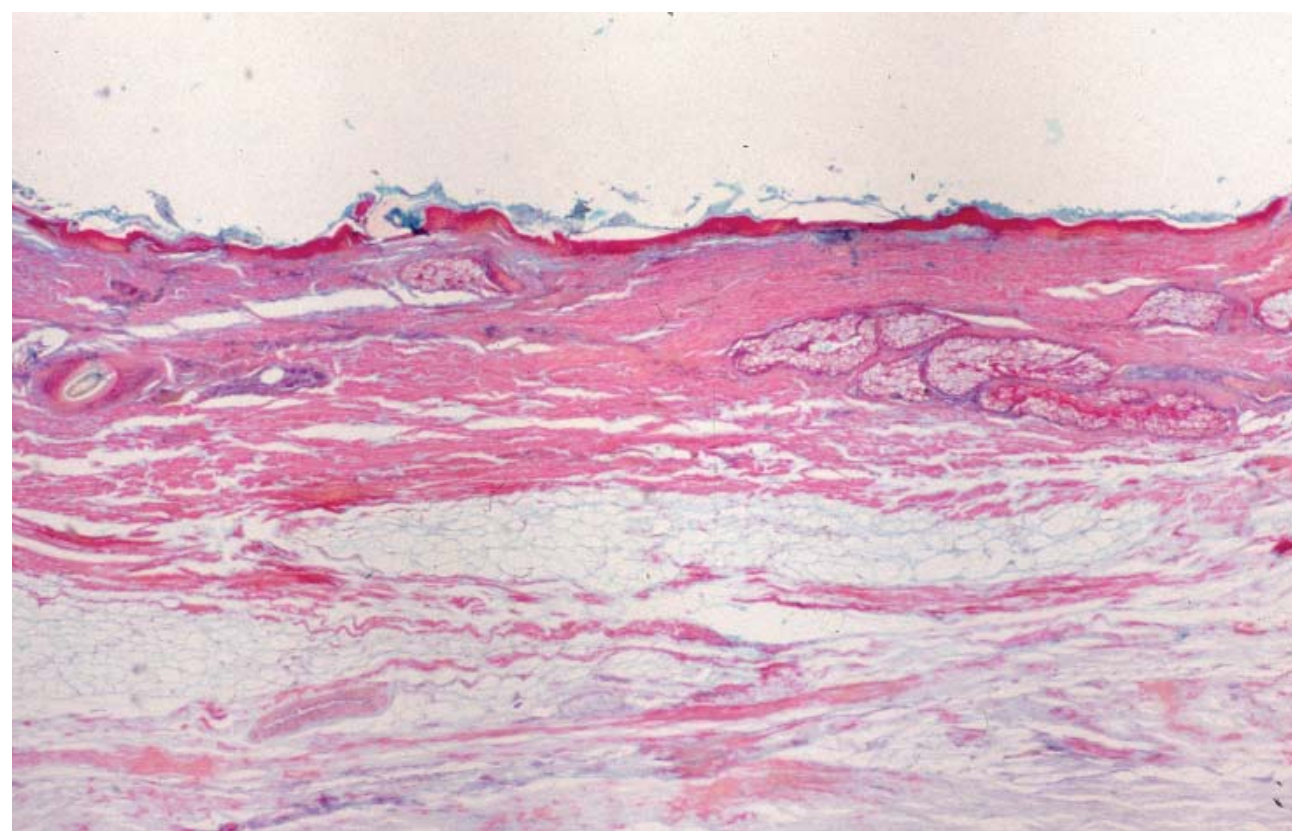

Figura 1.- Surco de ahorcadura: aplastamiento y metacromasia* positiva de los estratos epidérmico y dérmico (Técnica de Poley).

*Metacromasia: cambios de afinidad tintorial del tejido cutáneo y subcutáneo, asociado a presión mecánica o térmica. Es un marcador/indicador de lesión, no inequivocamente vital pues también en lesiones postmortem e incluso en situaciones de desecación o deshidratación (por si solo no es demostrativo). 


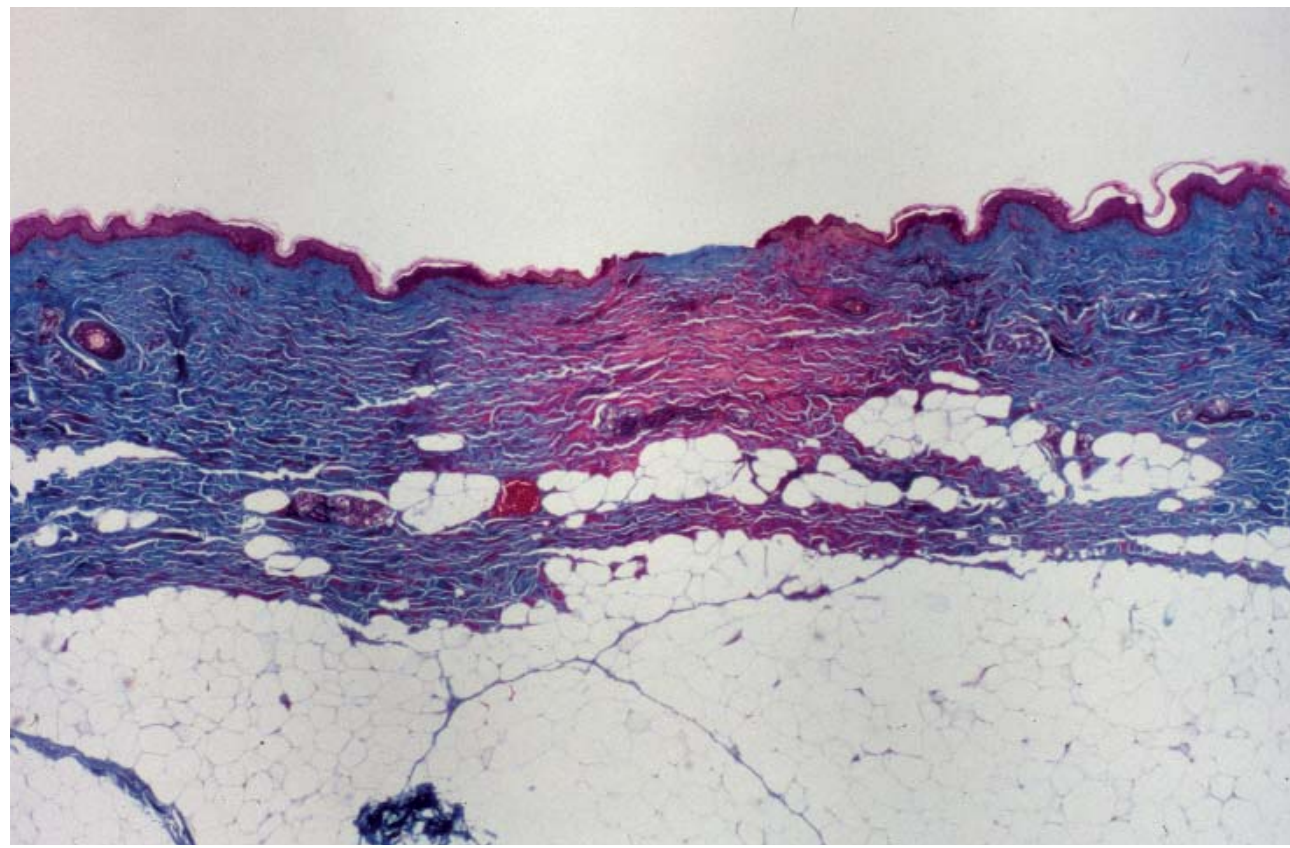

Figura 2.- Marca de estrangulación manual en piel: metacromasia positiva focal (corresponde a zona de color fucsia, que contrasta con el resto de la dermis de color azul) (Tricrómico de Masson).

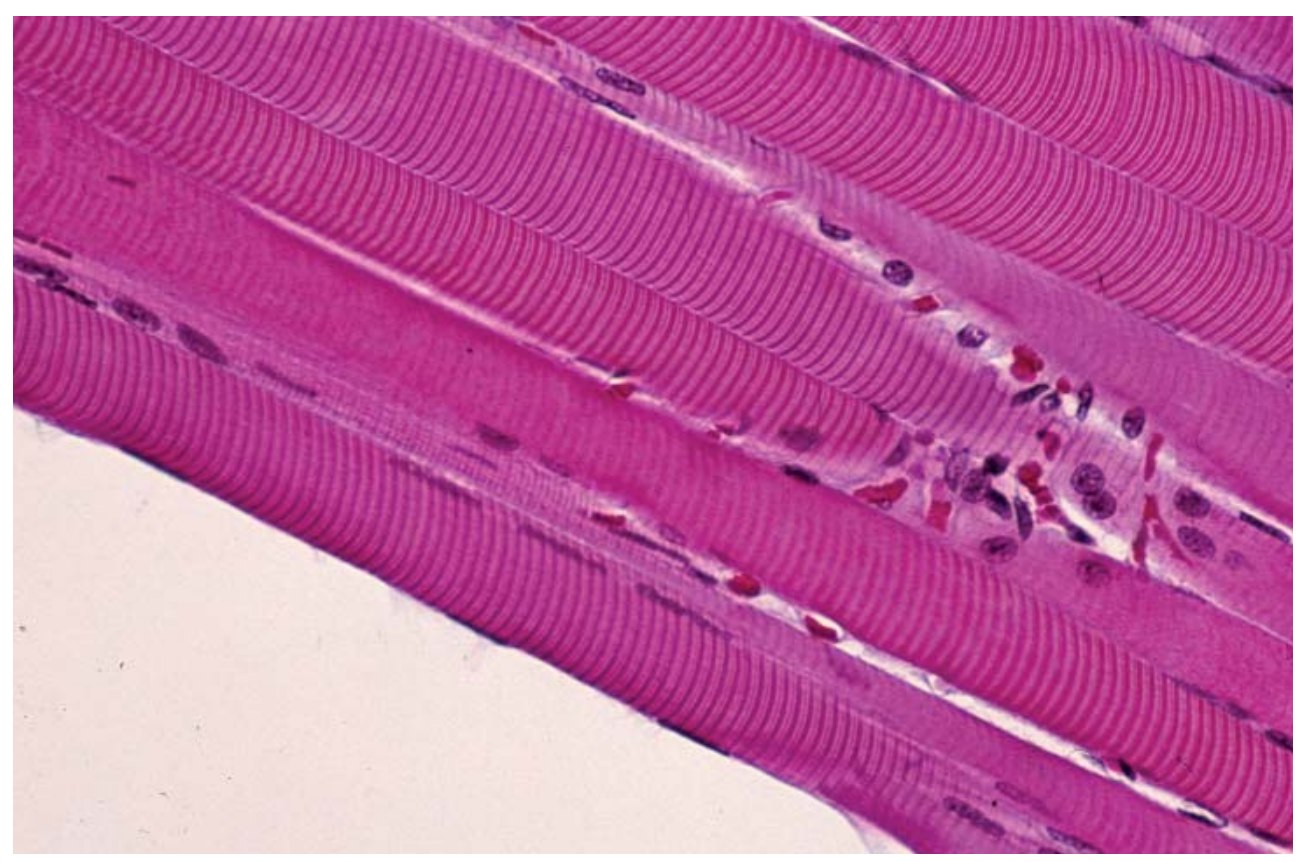

Figura 3.- Imagen microscópica control de músculo esquelético (esternocleidomastoideo), donde se aprecian sus principales características: núcleos periféricos, estriación sarcomérica, células satélites y capilares (Tricrómico de Masson). 


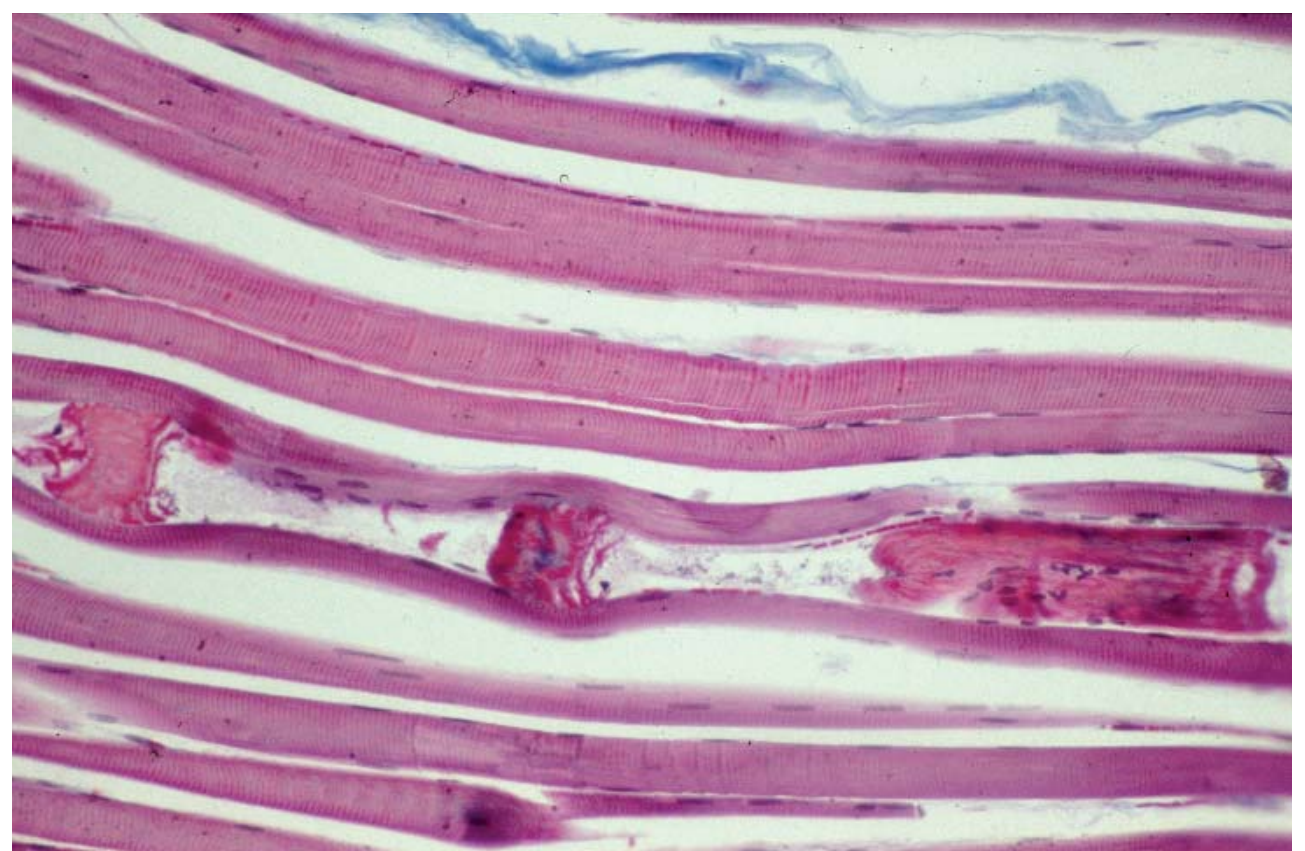

Figura 4.- Lesión muscular en ahorcadura: degeneración fibrilar segmentaria y discoide de distribución parcheada (Tricrómico de Masson).

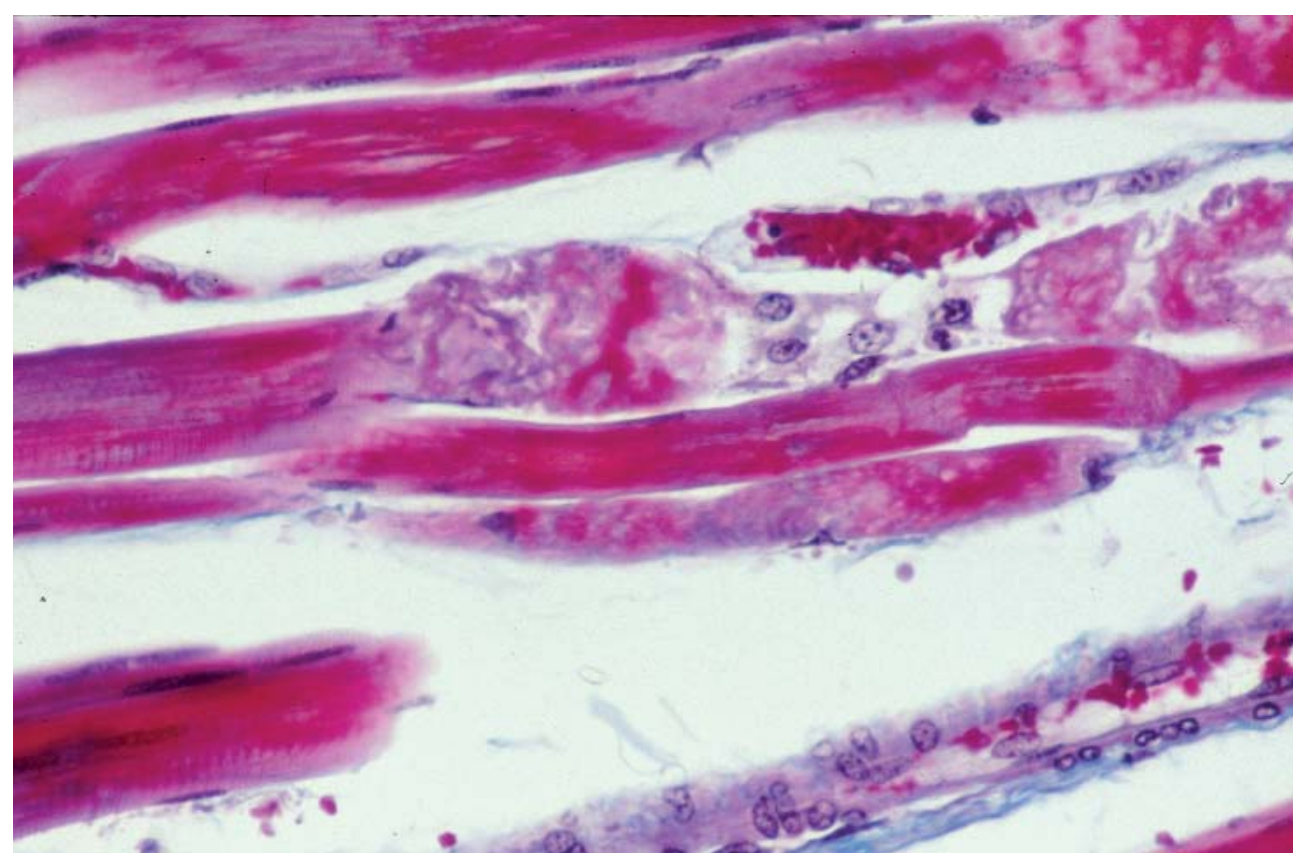

Figura 5.- Detalle de degeneración fibrilar en un caso de ahorcadura con 3 días de supervivencia (Tricrómico de Masson). 


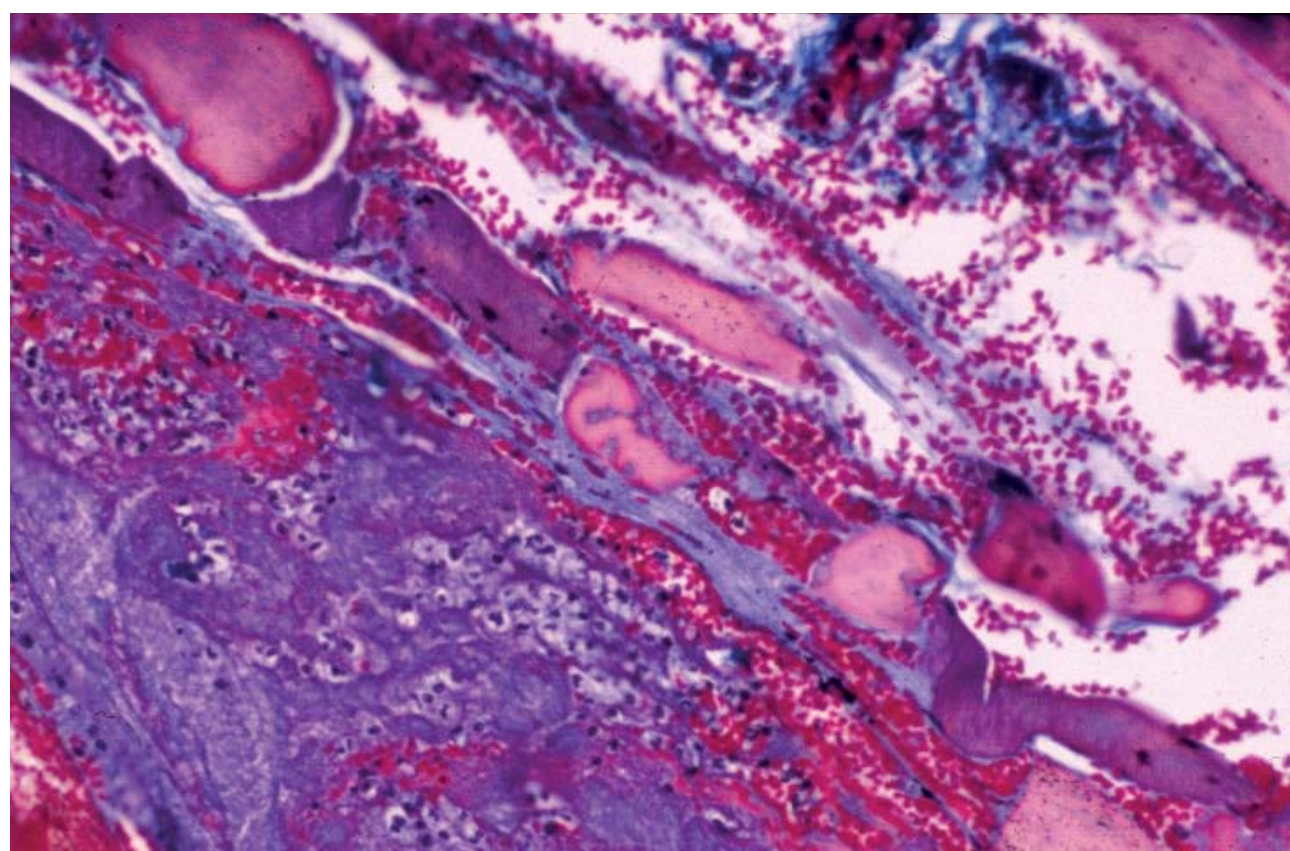

Figura 6.- Lesión muscular en intento de suicidio con arma blanca y posterior ahorcadura: fibras con degeneración fibrilar y/o aspecto hialino e infiltración hemorrágica, que muestra coágulo fibrino-plaquetario (tricrómico de Masson).

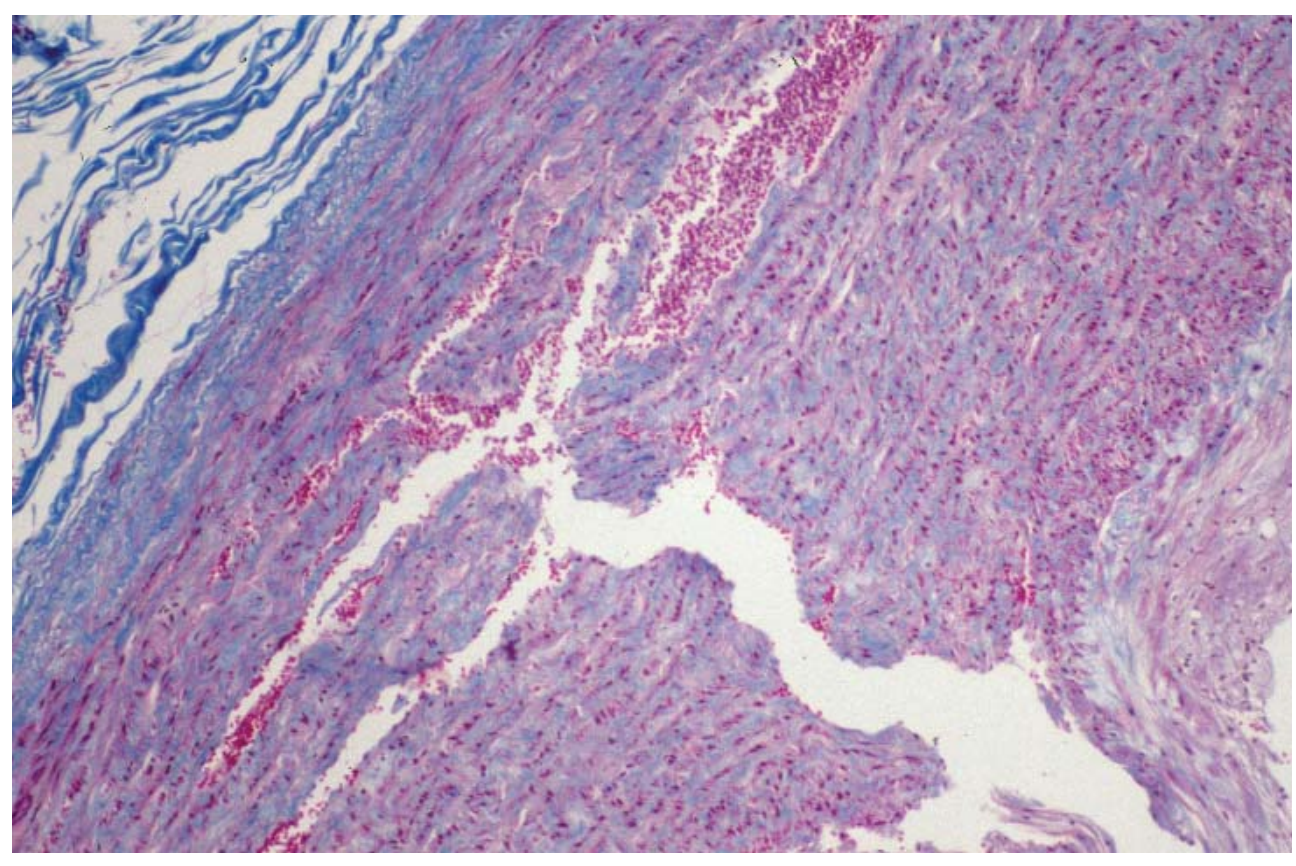

Figura 7.- Carótida primitiva: desgarro íntimo-medial transversal en ahorcadura, donde se aprecian restos hemáticos entre los bordes del desgarro (Tricrómico de Masson). 


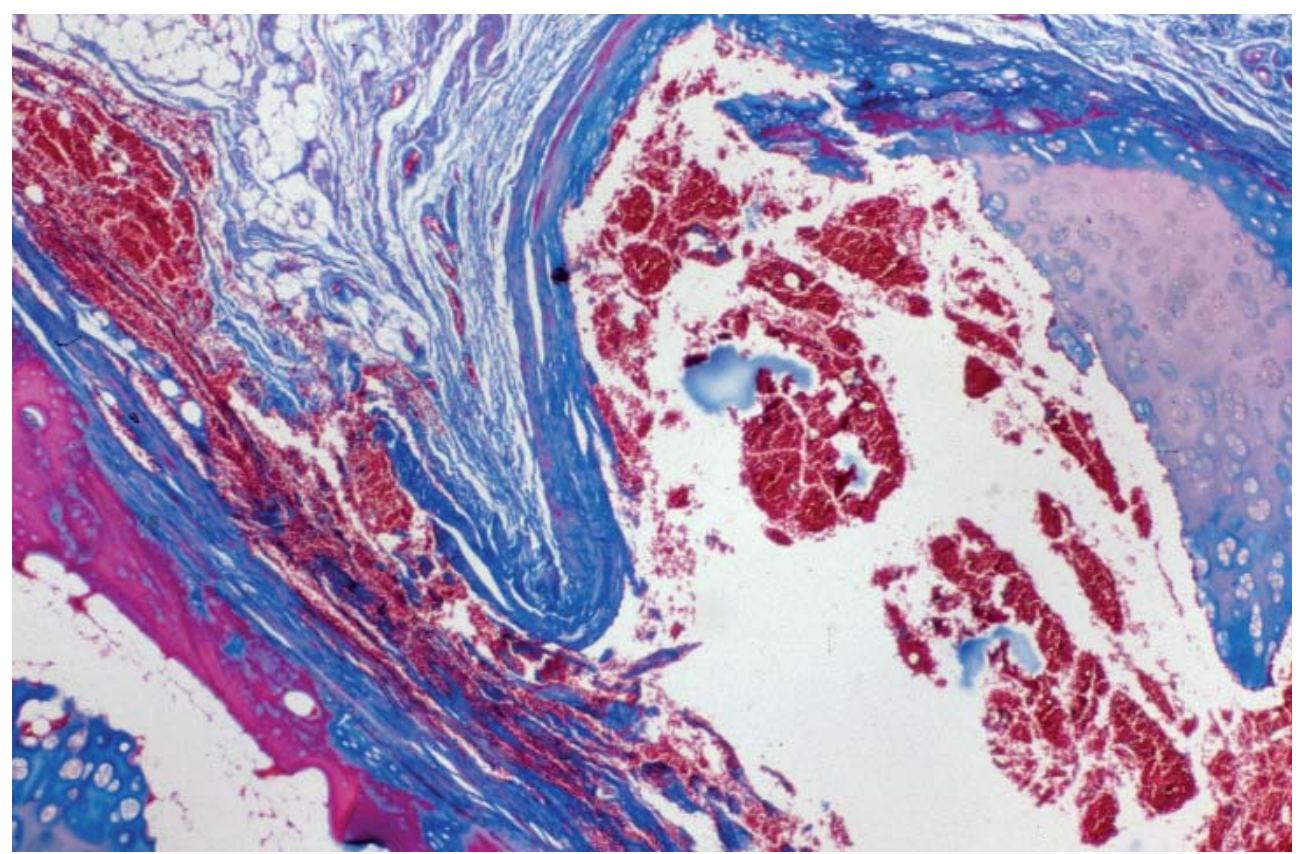

Figura 8.- Ahorcadura accidental: asta superior del tiroides, osificada, con rotura de su extremo e infiltración hemorrágica asociada, a nivel epi, intra y subperiostal (tricrómico de Masson). 